\title{
Nacionalismo e indigenismo en el gobierno del MAS
}

\section{Nationalism and indigenism in the MAS government}

\section{Fernando Mayorga y Benjamín Rodríguez}

Fernando Mayorga es sociólogo por la Universidad Nacional Autónoma de México (UNAM) y doctor en Ciencia Política por la Facultad Latinoamericana de Ciencias Sociales (FLACSO), catedrático en la Carrera de Sociología y Director General del Centro de Estudios Superiores Universitarios (CESU) en la Universidad Mayor de San Simón (UMSS), Bolivia.

E-mail: fermayorgau@gmail.com

\section{resumen}

En los últimos años se ha modificado el mapa político de América latina con resultados electorales que indican una idea genérica de "giro a la izquierda", imponiendo paulatinamente una taxonomía que distingue gobiernos socialdemócratas y gobiernos populistas. En Bolivia el arribo al gobierno del Movimiento al Socialismo (MAS) en enero de 2006 y la reelección presidencial de Evo Morales, despliega el proceso de una profunda reforma estatal que articula las demandas sociales en torno al nacionalismo $\mathrm{y}$ al indigenismo. La gestión gubernamental se define por diversos rasgos de progresismo, pero se perciben tendencias más extremas. La reorganización estatal de los poderes públicos es determinada por un marcado presidencialismo que influye en el Congreso y presiona al sistema judicial. La agenda del partido de gobierno se despliega en dos líneas de acción: la generación de excedente económico en procesos de industrialización con protagonismo estatal y la distribución de ingresos fiscales mediante políticas sociales con cariz popular. La política exterior se torna afín a Venezuela y Cuba, y se reafirma en un discurso que exalta la soberanía. Si bien la gestión de gobierno ha promovido cambios y logros en un país de difícil gobernabilidad, queda pendiente el proceso más complejo de la construcción de una nueva institucionalidad en el Estado Plurinacional de Bolivia.
Benjamín Rodríguez es sociólogo por la Universidad Mayor de San Simón (UMSS) de Cochabamba, Bolivia.

E-mail: benjo.dorf@gmail.com

\section{summary}

During the last few years the political map in Latin America has been modified thru electoral results which provide the general idea of a "left turn", imposing gradually a taxonomy that distinguishes social democrat governments from populist governments. In Bolivia, Movimiento al Socialismo's arrival to the government in January 2006 and Evo Morales presidential reelection, unfolds the process of a profound state reform jointing social demands around nationalism and indigenism. The governmental management is defined by diverse progressivism outlines, but also unveils extreme tendencies. The public power reorganization is defined by a manifest presidentialism, influencing parliament and pressing on judicial system. The government party's agenda unfolds in two action lines: economic excedent generated in industrialization process along with high state protagonism, and fiscal income distribution thru popular social policy. Foreign policy turns to Venezuela and Cuba, while it reaffirms on a speech exalting sovereignty. Governmental management has promoted changes and achievements in a country of difficult governability, albeit the complex construction process of a new institutionality still remains unsettled in Plurinational State of Bolivia.

\section{keywords}

State Plurinational / Evo Morales / Movimiento al Socialismo / progressivism / indigenism /

nationalism / public policy / Bolivia al Socialismo / progresismo / indigenismo / nacionalismo / políticas públicas / Bolivia 
Desde el arribo del Movimiento Al Socialismo (MAS) al gobierno en enero de 2006 y con la reelección presidencial de Evo Morales en diciembre de 2009, en ambos casos con mayoría absoluta de votos, en Bolivia se despliega un proceso de profunda reforma estatal. Este proceso se canalizó entre 2006 y 2007 a través de una Asamblea Constituyente que redactó un nuevo texto constitucional, aprobado mediante referéndum, en enero de 2009. La nueva Constitución se implementa desde enero de 2010 en un contexto político caracterizado por el predominio del MAS cuyo proyecto ocupa el centro del espacio de discursividad política.

Los antecedentes de este proceso se remontan a la revuelta popular de octubre de 2003 que derivó en la renuncia del presidente Sánchez de Lozada y el espacio discursivo se dividió entre las denominadas "agenda de octubre" (nacionalización y asamblea constituyente) y "agenda de enero" (autonomías departamentales y elección de prefectos), las que tenían sus respectivos bloques de actores políticos y sociales. En el primer caso, partidos de izquierda como el MAS y organizaciones sociales, principalmente campesinos e indígenas que conforman la principal base social de apoyo a Evo Morales. En el segundo caso, sectores urbanos, organizaciones regionales, grupos empresariales y fuerzas políticas tradicionales. En el transcurso del tiempo ambas agendas se han ido materializando porque fueron articuladas al proyecto político del MAS e incorporadas en el nuevo texto constitucional. La nacionalización de recursos naturales y empresas estratégicas es política gubernamental desde mediados de 2006 aunque su aplicación es variada. La nueva Constitución Política del Estado (CPE) tiene un sello indigenista y también se han constitucionalizado las autonomías departamentales, que incluyen la elección directa de prefectos/gobernadores.

Siguiendo rutas diversas, el MAS articuló las demandas de ambas "agendas" en torno al nacionalismo y al indigenismo y el conjunto de los discursos políticos se ordena por afinidad o cuestionamiento en torno a estos ejes. Veamos la parte del nacionalismo. La política de nacionalización de los recursos naturales se inició en el sector de hidrocarburos y no tiene detractores, por lo tanto es improbable un retorno a posturas antiestatistas en el mediano plazo y no existen actores políticos que enarbolen la defensa del neoliberalismo, ni siquiera sectores empresariales. La política económica del gobierno recupera el paradigma desarrollista del nacionalismo revolucionario, vigente en el país desde los años cincuenta del siglo pasado y se expresa en una visión de tipo industrialista, aunque adecuado a las nuevas condiciones provistas por la globalización.

En cuanto al indigenismo, la centralidad de las reivindicaciones étnicas en la CPE muestra el carácter irreversible de la inclusión de las demandas e identidades campesinas e indígenas que fueron reconocidas como derechos colectivos. El Estado republicano ha sido redefinido como Estado Plurinacional; no obstante ese rasgo todavía es más retórica que realidad institucional y su materialización es lenta. Por ahora se expresa en el reconocimiento de circunscripciones especiales indígenas que constituyen alrededor del 5\% de diputados de la Asamblea Legislativa Plurinacional y en la existencia de cuotas étnicas en varios órganos del Estado, incluyendo el electoral y el judicial. 
Bajo estos criterios analizamos las peculiaridades de la gestión gubernamental del MAS que inició en enero de 2010 su segundo período constitucional para reflexionar en torno a su carácter progresista, habida cuenta que se incluye en la lista de "gobiernos de izquierda" que predominan en América latina.

\section{Rasgos de la gestión del mas en términos de progresismo}

La idea más expedita del progresismo es que supone una izquierda moderada. Varias gestiones gubernamentales de países latinoamericanos se prestan para pesquisas y análisis de rasgos sutiles ajustables dentro este concepto. La noción de "giro a la izquierda" es otra manera de referirse a las victorias electorales que encumbró en el gobierno a Chávez en Venezuela, Correa en Ecuador, Lugo en Paraguay, Vázquez en Uruguay, entre otros. En Bolivia estas sutilezas tomaron formas que van más allá de leves señales de izquierda, por esto, la tarea se extiende también a revelar las sutilezas que indiquen tendencias más extremas, particularmente por el componente campesino e indígena del partido de gobierno, de los sectores sociales que impulsan su proyecto político y por el perfil del liderazgo de Evo Morales. El hecho es que no se puede decir que esta gestión no es progresista, pero hay aspectos importantes que van más allá de este rasgo. Los rasgos inmediatos que pueden señalar a la actual gestión como progresista son los que privilegian un mayor rol del Estado y buscan igualitarismo a través de políticas públicas, pero existen muchas formas de hacerlo. En Bolivia se tienen más casos especiales que la homogeneidad de señales asibles en un solo término, por tanto, se hace necesaria una mezcla y simultaneidad de conceptos para definir la gestión gubernamental. Se intenta elaborar un retrato temporal y dinámico que revele rasgos de esta gestión con un enfoque que piensa el progresismo pero que se abre a otras dimensiones, cuidando no exponer el término a lo políticamente correcto, ni aproximarlo a la apócope "progre", tan usado como categoría caricatura que perfila más una ligera cosmovisión que ideología profunda.

El gobierno busca mejorar la calidad de vida que es definida como sumaj kausay en quechua o sumaj khamaña en aymara y que se traducen como "vivir bien", un principio extraído de las tradiciones andinas, adoptado y convertido en idea fuerza del discurso oficialista. Este principio va conectado también al rasgo progresista de inquietud constante por la ecología; los discursos indígenas sostienen que, la Pachamama está enferma ${ }^{1}$, que la "madre tierra" se muere.

Evo Morales sostiene que el capitalismo es el modo económico que está destruyendo el planeta. Progresista de sentido ecológico, fue la convocatoria a la Primera Conferencia Mundial de los Pueblos sobre el Cambio Climático y los derechos de la Madre Tierra, que se realizó en Cochabamba en abril de 2010 como respuesta al fracaso de la cumbre de gobernantes en Copenhague. Evo Morales declaraba: "Guiados por los principios de solidaridad, justicia y respeto por la vida, serán capaces de salvar a la humanidad, a la Madre Tierra", [la conferencia], "analizará las causas estructurales y sistemáticas que provocan el cambio climático, y propondrá medidas de fondo que posibiliten el bienestar de toda la humanidad en armonía con la naturaleza". ${ }^{2}$ Y de aquí, el progresismo vernáculo tuvo la pretensión de 
proyectarse al mundo: "Bolivia espera que en esta conferencia se apruebe una Declaración Universal de Derechos de la Madre Tierra y se integre un Tribunal Internacional de Justicia Climática con el objetivo de sancionar a los países industrializados que contaminan el medio ambiente". ${ }^{3}$ Los asistentes representativos a esta cumbre climática fueron escasos. Las conclusiones no tuvieron la repercusión internacional que se esperaba. La oposición criticó a la conferencia por politizada. $\mathrm{Y}$ algunos dirigentes indígenas e intelectuales locales cuestionaron, en el seno de la Conferencia, la contradicción entre el discurso ecologista de Evo Morales en el escenario global y la política industrializadora y extractivista de los recursos naturales que su gobierno impulsa en el país.

Esta gestión se ha empeñado en el igualitarismo, la igualdad de oportunidades para todos, y la retórica oficialista sostiene que su horizonte es la implantación del "socialismo comunitario" bajo el poder de los movimientos sociales; no obstante esta idea no ha pasado de ser una mera consigna. Lo progresista también pasa de largo lo jurídico para atender la emergencia de la pobreza; el gobierno ha implementado bonos, seguros, acciones y políticas que asisten a grupos en situación de vulnerabilidad o desventaja, muchas veces tomando la vía directa del decreto presidencial.

Respecto a la proyección de un mayor rol del Estado en la economía, el vicepresidente García Linera, declaró que: "El Estado es la empresa más grande de Bolivia. El Estado administra cerca de 14.000 millones de dólares. Ninguna empresa puede competir con el Estado y qué bien que sea así". ${ }^{4}$ El Estado empieza a intervenir significativamente en el mercado. El Estado regula las importaciones y exportaciones mediante decretos y frecuentemente participa en la venta de productos básicos, a fin de regular los precios al consumidor, en desmedro de las grandes empresas. Sin embargo, la nacionalización del sector hidrocarburífero, en apariencia dura, fue una transacción y conciliación de nuevos convenios sobre impuestos, en un marco legal y sin la toma de la infraestructura de las empresas extranjeras. El gobierno está en contra de la concentración de tierras y su política agraria no solamente favorece el acceso comunitario a la tierra sino que la CPE limita la posesión a una extensión máxima de cinco mil hectáreas. El centralismo estatal ha permanecido como una visión de conjunto; durante la primera gestión ha sido férrea la resistencia del gobierno a la descentralización a través de autonomías departamentales (provinciales) pese a una insistente demanda regional y a los conflictos que generaba. En la segunda gestión, es el propio gobierno quien impulsa la autonomía en varios niveles (departamental, regional, municipal e indígena) sólo que esta vez cuenta con un mayor control, que va desde la interpretación y manejo especial de los resultados electorales hasta juicios a autoridades opositoras.

El progresismo va en contra del conservadurismo; el gobierno desde su inicio manejó el discurso del "cambio" en las dimensiones económica, política y social. Ha evitado comulgar con políticas o dirigentes conservadores y arrasó con los partidos tradicionales. No hubo entendimiento ni convenios significativos con la oposición, la poca concertación que se logró fue para no sumir al país en mayores confrontaciones violentas. 
Cuando el gobierno se refiere a los derechos humanos reiteradamente busca llamar la atención sobre los derechos de indígenas y campesinos, en la idea de compensar aquella concepción de unos derechos humanos que en el pasado sólo llegaron a pocos privilegiados del área urbana. Está en contra de todo tipo de discriminación aunque es reacio a interpelar a los sectores mestizos; ha realizado un permanente trabajo para la inclusión de indígenas, campesinos y grupos en estado de vulnerabilidad, con estrategias políticas, mediáticas, discursivas, legales y administrativas que tuvieron su expresión en la Asamblea Constituyente y en las instancias del poder ejecutivo. Respecto a la igualdad de género, destaca la presencia de muchas mujeres en puestos estratégicos en la Asamblea Constituyente, ministerios y cargos públicos. En su segundo mandato, se conformó el primer gobierno con paridad de género en carteras ministeriales, donde participan diez mujeres, de las cuales cuatro son indígenas, empero, queda el desafío de lograr mejores condiciones para la mujer en el interior de las comunidades rurales. Respecto a los derechos de los emigrantes, con el padrón electoral biométrico se ha logrado el derecho a la votación de los bolivianos residentes en el exterior. En general, esta gestión ha buscado mejoras en el acceso a la educación, salud pública, agua potable, saneamiento básico, tanto así, que muchas veces el discurso y las acciones de Evo Morales se desviaron hacia el quehacer municipal y local donde los recursos públicos se combinan con ayuda de los gobiernos de Venezuela y Cuba.

\section{Problemas de equilibrio y colaboración entre los poderes públicos}

La República de Bolivia cambió su nombre por el de Estado Plurinacional de Bolivia. La nueva CPE cambió la nomenclatura de los poderes del Estado a Órgano Legislativo Plurinacional, Órgano Ejecutivo Plurinacional y Órgano Judicial Plurinacional, y creó un cuarto poder, el Órgano Electoral Plurinacional.

Antes de la reelección, Evo Morales declaró: "Algunos dicen que tenemos el poder, falso, no estamos en el poder, solo tenemos el gobierno, el poder ejecutivo. Lo que se puede hacer por decretos, lo estamos haciendo, lo que se puede hacer con ley no se puede hacer. En las elecciones de diciembre de este año (2009), el poder que tenga el pueblo significa que tengamos el poder ejecutivo, el poder legislativo y el poder judicial. Así el pueblo boliviano tendrá el poder para hacer justicia con los trabajadores". ${ }^{5}$ Esta aspiración expresaba el deseo de no repetir escenarios de la primera gestión 2006-2009, donde se dio la figura de "gobierno dividido" porque el MAS dominaba la Cámara de Diputados, pero la oposición lo hacía en la Cámara de Senadores 6 (ver Cuadro 1).

Esta situación dificultó la aprobación de leyes por parte del oficialismo y fue empujado a dictar decretos supremos desde el poder ejecutivo, muchas veces controvertidos y cuestionados por la oposición debido a su inconstitucionalidad. Así, aplicó más de mil decretos, donde sobresalen: D.s. 28.701 de 1 de mayo de 2006, nacionalización de los hidrocarburos; D.s. 29.544 de $1^{\circ}$ de mayo de 2008, nacionalización del paquete accionario de Eti Eurotelecom Internacional en la Empresa Nacional de Telecomunicaciones; D.s. 29.480 de 19 de marzo de 2008, prohibición 
de la exportación de cuatro tipos de aceites, que pretendía frenar el incremento de precios pero vulnerando los mercados de exportación de los sectores empresariales. De manera reiterada, el poder ejecutivo ha tomado decisiones que correspondían al poder legislativo; diversas temáticas controvertidas que merecían un proceso de deliberación para elevarse a rango de ley fueron aplicados como decretos. El D.s. 29.322 del 24 de octubre de 2007, sobre la redistribución de los recursos provenientes de impuestos sobre los hidrocarburos, causó controversias y protestas regionales. Esta forma de gobernar a partir del ejecutivo está siendo utilizada también durante el segundo mandato de Morales, aún teniendo mayoría en ambas Cámaras.

\section{Cuadro 1. Elecciones generales 2005 y 2009. Representación parlamentaria}

\begin{tabular}{|c|c|c|c|c|}
\hline \multicolumn{5}{|c|}{ Elecciones Nacionales 2005 y Representación parlamentaria, 2005-2010 } \\
\hline \multirow[t]{2}{*}{ Agrupación política } & \multirow[t]{2}{*}{ Votos } & \multirow[t]{2}{*}{ Porcentaje } & \multicolumn{2}{|c|}{$\begin{array}{r}\text { Representación en el } \\
\text { Parlamento }\end{array}$} \\
\hline & & & Diputados & Senadores \\
\hline MAS & $1^{\prime} 544,374$ & $53,74 \%$ & 72 & 12 \\
\hline PODEMOS & 821,745 & $28,59 \%$ & 43 & 13 \\
\hline $\mathrm{UN}$ & 224,090 & $7,79 \%$ & 8 & 1 \\
\hline MNR & 185,859 & $6,47 \%$ & 7 & 1 \\
\hline Otras agrupaciones & 97,733 & $3,40 \%$ & -- & -- \\
\hline Total votos válidos & 2'873.801 & $99,99 \%$ & & \\
\hline Total escaños & & & 130 & 27 \\
\hline \multicolumn{5}{|c|}{$\begin{array}{l}\text { Elecciones generales } 2009 \text { y escaños en la Asamblea Legislativa Plurinacional } \\
2010-2015\end{array}$} \\
\hline \multirow[t]{2}{*}{ Agrupación política } & \multirow[t]{2}{*}{ Votos } & \multirow[t]{2}{*}{ Porcentaje } & \multicolumn{2}{|c|}{$\begin{array}{r}\text { Representación en la } \\
\text { Asamblea Legislativa } \\
\text { Plurinacional }\end{array}$} \\
\hline & & & Diputados & Senadores \\
\hline MAS-IPSP & $2,943,209$ & $64,22 \%$ & 88 & 26 \\
\hline PPB-CONVERGENCIA & $1,212,795$ & $26,46 \%$ & 37 & 10 \\
\hline UNIDAD NACIONAL & 258,971 & $5,65 \%$ & 3 & -- \\
\hline ALIANZA SOCIAL & 106,027 & $2,31 \%$ & 2 & -- \\
\hline Otras agrupaciones & 97.733 & $1,35 \%$ & -- & -- \\
\hline Total votos válidos & $4,582,786$ & $94,31 \%$ & & \\
\hline Total escaños & & & 130 & 36 \\
\hline
\end{tabular}

Fuente: Elaboración propia con base en datos CNE.

A partir de la segunda gestión iniciada en enero de 2010, el MAs tiene el control total de ambas cámaras de la Asamblea Legislativa Plurinacional. Esta primacía en ambas cámaras permite la aprobación acelerada de los proyectos de ley gubernamentales, pero frena la necesaria deliberación. La Asamblea Legislativa tenía como principal tarea aprobar leyes que respalden la nueva $\mathrm{CPE}$, sin embargo, aprobó leyes cortas o transitorias que han determinado un mayor control del 
oficialismo sobre las instituciones del Estado, como el Órgano Judicial, el Tribunal Constitucional, la Fiscalía. Esta situación ha puesto en duda el equilibrio, independencia y armonía de los poderes públicos del Estado. Se teme una tendencia a la organización de Poderes en forma de cascada, por un marcado presidencialismo que influye en el congreso y presiona al sistema judicial, generando una suerte de colaboracionismo entre poderes públicos, sujetos a la voluntad política del actor que domina el manejo del Estado. Hasta fines de julio de 2010 se tiene prevista la aprobación y promulgación de cinco leyes importantes referidas a los Órganos Judicial y Electoral, al Tribunal Constitucional, al Régimen Electoral y la Ley Marco de Autonomías y Descentralización que fijarán los rasgos de la nueva institucionalidad estatal y el tipo de relación entre Órganos del Estado.

El tema del poder judicial generó amplios debates y algunos conflictos. Desde la primera gestión de Evo Morales se dieron casos de acefalías en altas instancias de este poder, el oficialismo no coincidía con los magistrados elegidos en anteriores gestiones, un permanente conflicto que terminó en juicios por prevaricato a los magistrados del Tribunal Constitucional, quienes renunciaron dejando paralizada la institución. El hecho generó reacción inmediata de la oposición que criticó estas acciones como atentados contra la institucionalidad y el Estado de Derecho. Otra situación similar de acefalía se presentó en la Corte Suprema de Justicia y en el Consejo de la Judicatura, y fueron tratadas en la Asamblea Plurinacional en 2010. Estos casos aceleraron la promulgación de una "Ley Corta" que dio potestad al Presidente del Estado para nombrar autoridades interinas en cargos acéfalos sin participación del Órgano Legislativo. La implicancia de esta ley tuvo prontas repercusiones y la oposición puso en duda la independencia del órgano judicial. Un dato importante es que se incorpora la elección de magistrados del Tribunal Supremo de Justicia por voto popular, programada para el 5 de diciembre de 2010. Los candidatos a magistrados serán preseleccionados por el congreso, y aunque los requisitos son no pertenecer a organizaciones políticas, ni realizar propaganda por su candidatura, las tendencias políticas dominantes inclinarán la balanza en el voto. Estas circunstancias podrían ampliar la influencia del MAS en el Órgano Judicial.

La aprobación de la Ley del Tribunal Constitucional (julio 2010) que determina que el intérprete auténtico de la CPE es la Asamblea Legislativa redujo las atribuciones del Tribunal Constitucional a intérprete jurídico, supeditándolo virtualmente al Órgano Legislativo. Entre las acciones polémicas y aceleradas de la Asamblea Legislativa está la prórroga del mandato del Fiscal General, pese a que correspondía una nueva designación desde una terna sometida a votación legislativa. Según la oposición, esto hizo expedito un enérgico seguimiento judicial y persecución política a sus líderes. La Fiscalía ha efectuado acusaciones que van desde corrupción, malversación de fondos (por la realización de referendos autonómicos departamentales calificados de ilegales), hasta vínculos con supuestos mercenarios separatistas. También desde el gobierno, vía ministerio público, se han encausado procesos judiciales a cuatro ex presidentes. Asimismo, se aprobó la ley anticorrupción "Marcelo Quiroga Santa Cruz", que tiene carácter retroactivo; 
otra vez la oposición denunció esta norma como instrumento de persecución política que sería utilizado contra sus candidatos. Los enjuiciamientos tocaron también las elecciones departamentales y municipales de abril 2010 porque varios alcaldes y gobernadores de oposición fueron suspendidos mediante acciones legales. Todo lo anterior evidencia una acción política jurídica con rasgos de uso instrumental del Órgano Judicial.

La coexistencia y convivencia del derecho positivo con el derecho consuetudinario en el país, todavía presenta dificultades y complica al poder judicial. La justicia comunitaria de usos y costumbres de pueblos indígenas y originarios está vigente por principio constitucional, y tiene potestades muy próximas a la justicia positiva, quedando pendiente la aprobación de una Ley de Deslinde Jurisdiccional para viabilizar el pluralismo jurídico que consagra la nueva CPE. Las dificultades de una articulación virtuosa se hacen visibles de manera constante. A manera de ejemplo citamos un caso dramático y revelador de confusión judicial, que se dio a finales de mayo del presente año. Se trata de la tortura y linchamiento de cuatro policías en el municipio de Uncía, población cercana a la frontera con Chile. Los dirigentes locales utilizaron argumentos de justicia comunitaria y autonomía indígena para justificar sus acciones criminales. Aunque el gobierno declaró que la justicia comunitaria no permite linchamientos; los comunarios sí lo hicieron y retuvieron por varios días los cuerpos torturados, y durante el conflicto declararon a su poblado zona de libre tránsito para el contrabando de vehículos. Autoridades ministeriales y policiales fueron acusadas de sostener una dilatada negociación que diluyó la posibilidad de un rescate con vida de las víctimas. La autoridad del Estado y su fiscalía -entrampada entre sus propias reglas- dieron otra muestra del desconcierto que vive el país en materia de justicia.

Por dictado constitucional surge una nueva institución en la presente gestión: el Órgano Electoral Plurinacional. Esta institución viene a ser la nueva expresión de la Corte Nacional Electoral, organismo independiente del gobierno, que tuvo un rol activo en una década de crisis y conflicto, en que se dieron más procesos electorales que en cualquier otra década de la historia republicana. La Corte tuvo un rol sustancial al hacer posible eventos de decisión poblacional que determinaron el decurso de la transición estatal, entre los cuales se cuentan las elecciones para Presidente y Prefectos en 2005, cuando por primera vez se eligieron autoridades departamentales; el Referéndum de Autonomías Departamentales; y las Elecciones para la Asamblea Constituyente en 2006. Luego tuvo que encarar un complicado proceso de Referéndum de Revocatoria de Mandato Popular, en el año 2008, evento que planteaba al elector, revocar o ratificar el mandato del presidente y del vicepresidente de la República, así como de los prefectos departamentales. Este proceso fue cuestionado por la oposición, en cuanto a la confiabilidad del padrón electoral ${ }^{7}$, situación que impulsó la realización de un padrón biométrico que daría mayor confianza a los procesos electorales. Un logro importante de este organismo fue la implementación del padrón biométrico y la inscripción de ciudadanos bolivianos residentes en el exterior. 
La Corte llevó a cabo otras consultas electorales decisivas: el Referéndum Constitucional en enero de 2009, donde fue aprobada la nueva CPE y las Elecciones Generales en 2009, que incluía un nuevo Referéndum de Autonomías Departamentales. Y en abril de 2010 se realizó la elección de gobernadores, asambleístas departamentales y alcaldes municipales según el régimen de autonomías aprobado en el nuevo texto constitucional. Opositores de departamentos de occidente cuestionaron la imparcialidad del Órgano Electoral Plurinacional por la aplicación de una norma que favorecía a las fuerzas mayoritarias en la asignación de escaños en las elecciones departamentales. Esta decisión favoreció al MAS en la región occidental del país y a los opositores de la región oriental y sur, pero perjudicaba a las fuerzas políticas emergentes y con menor votación, menoscabando el pluralismo político en el nivel subnacional (Ver Cuadro 2).

En la primera gestión de gobierno de Evo Morales se exacerbaron diferencias regionales en torno al proceso de autonomía que inició el departamento de Santa Cruz, secundado por los departamentos de Beni, Pando y Tarija, que juntos se denominaron "la media luna". La demanda autonómica tiene como antecedente el potencial económico, sobretodo agrícola e industrial, del departamento de Santa Cruz y la riqueza petrolera de Tarija, mientras que Beni y Pando se sumaron por afinidades económicas, político-ideológicas y regionales. En el año 2005, de manera paralela a la elección presidencial, por primera vez en la historia nacional se eligieron autoridades departamentales. Fueron seis de nueve departamentos donde vencieron candidatos opositores; esta situación complicaría las relaciones entre oficialismo y oposición. Los resultados electorales determinaron una parcial "división vertical de poderes". Ante un cuadro de creciente polarización en el que se oponía la demanda regional de autonomía departamental al centralismo estatal se produjeron graves conflictos en la Asamblea Constituyente; finalmente, se aprobaron las autonomías departamentales; no obstante el oficialismo también incorporó autonomías regionales e indígenas, además de mantener las de carácter municipal.

El conflicto regional alcanzó su punto más crítico entre mayo y septiembre de 2008 , cuando los departamentos de "la media luna" convocaron a referendos locales para aprobar sus propios estatutos autonómicos. Por su parte, el gobierno central, llamó a un Referendo Revocatorio de Mandato Popular para dirimir en las urnas esta pugna vertical de poderes. Los resultados revocaron a dos prefectos opositores y ratificaron al presidente, dos prefectos oficialistas y a cuatro prefectos opositores de la denominada media luna (ver Cuadro 3). En septiembre de 2008, los sectores opositores regionales provocaron diversos focos de conflicto en varios departamentos. ${ }^{8}$ Entre ellos está la toma violenta de instituciones públicas reclamando el respeto a los estatutos autonómicos, por un lado, y cuestionando la nueva CPE, por otro; en ambos casos el oficialismo y la oposición lanzaron mutuas acusaciones de ilegalidad e ilegitimidad. Esto determinó la necesidad de compatibilizar los estatutos autonómicos y la nueva Constitución en un pacto parlamentario que finalmente se logró en octubre de 2008. 
Cuadro 2. Asignación de escaños para Asambleístas Departamentales según los resultados de las Elecciones Departamentales de abril 2010. Dos alternativas de interpretación

\begin{tabular}{|c|c|c|c|c|c|c|}
\hline \multirow[b]{3}{*}{$\begin{array}{c}\text { Departamento/ } \\
\text { Partido }\end{array}$} & \multirow{2}{*}{\multicolumn{3}{|c|}{$\begin{array}{c}\text { Interpretación esperada por fuerzas } \\
\text { políticas emergentes } \\
\text { Asignación de escaños para la } \\
\text { Asamblea Departamental aplicando el } \\
\text { artículo } 38 \text { de la ley } 4.021\end{array}$}} & \multirow{2}{*}{\multicolumn{3}{|c|}{$\begin{array}{c}\text { Interpretación aplicada por la Corte } \\
\text { Nacional Electoral } \\
\text { Asignación de escaños para la Asamblea } \\
\text { Departamental aplicando las directivas } \\
\text { del presidente de la CNE }\end{array}$}} \\
\hline & & & & & & \\
\hline & $\begin{array}{c}\text { Asambleís- } \\
\text { tas por } \\
\text { población }\end{array}$ & $\begin{array}{l}\text { Asambleís- } \\
\text { tas por } \\
\text { territorio }\end{array}$ & $\begin{array}{c}\text { Total } \\
\text { Asambleís- } \\
\operatorname{tas}^{\mathrm{a}}\end{array}$ & $\begin{array}{l}\text { Asambleís- } \\
\text { tas por } \\
\text { población }\end{array}$ & $\begin{array}{c}\text { Asambleís- } \\
\text { tas por } \\
\text { territorio }\end{array}$ & $\begin{array}{l}\text { Total Asam- } \\
\text { bleístas }^{\mathrm{a}}\end{array}$ \\
\hline La Paz & 20 & 20 & 40 & 20 & 20 & 40 \\
\hline MAS-IPSP & 0 & 19 & 19 & 11 & 19 & 30 \\
\hline MSM & 11 & 1 & 12 & 6 & 1 & 7 \\
\hline UN & 5 & 0 & 5 & 2 & 0 & 2 \\
\hline MPS & 2 & 0 & 2 & 1 & 0 & 1 \\
\hline ASP & 1 & 0 & 1 & 0 & 0 & 0 \\
\hline MNR & 1 & 0 & 1 & 0 & 0 & 0 \\
\hline Cochabamba & 16 & 16 & 32 & 16 & 16 & 32 \\
\hline MAS-IPSP & 4 & 16 & 20 & 11 & 16 & 27 \\
\hline UN & 8 & 0 & 8 & 4 & 0 & 4 \\
\hline MSM & 3 & 0 & 3 & 1 & 0 & 1 \\
\hline MNR & 1 & 0 & 1 & 0 & 0 & 0 \\
\hline Chuquisaca & 9 & 10 & 19 & 9 & 10 & 19 \\
\hline MAS-IPSP & 2 & 9 & 11 & 6 & 9 & 15 \\
\hline C.S.T & 5 & 1 & 6 & 3 & 1 & 4 \\
\hline LIDER & 1 & 0 & 1 & 0 & 0 & 0 \\
\hline F-19 & 0 & 0 & 0 & 0 & 0 & 0 \\
\hline MSM & 1 & 0 & 1 & 0 & 0 & 0 \\
\hline Potosí & 16 & 16 & 32 & 16 & 16 & 32 \\
\hline MAS-IPSP & 6 & 16 & 22 & 11 & 16 & 27 \\
\hline AS & 6 & 0 & 6 & 3 & 0 & 3 \\
\hline FCRP & 2 & 0 & 2 & 1 & 0 & 1 \\
\hline A.C.U & 2 & 0 & 2 & 1 & 0 & 1 \\
\hline MNR & 0 & 0 & 0 & 0 & 0 & 0 \\
\hline Oruro & 16 & 16 & 32 & 16 & 16 & 32 \\
\hline MAS-IPSP & 4 & 15 & 19 & 10 & 15 & 25 \\
\hline MSM & 9 & 1 & 10 & 5 & 1 & 6 \\
\hline UN & 2 & 0 & 2 & 1 & 0 & 1 \\
\hline MNR & 1 & 0 & 1 & 0 & 0 & 0 \\
\hline
\end{tabular}

${ }^{a}$ Cada Asamblea Departamental tendrá además entre uno y cinco asambleístas elegidos mediante usos y costumbres por los pueblos indígenas originarios campesinos.

Fuente: Elaboración propia con base en F. Yaksic (2010). 
Cuadro 3. Resultados del Referéndum Revocatorio de Mandato Popular, 2008

\begin{tabular}{|c|c|c|c|c|c|}
\hline \multirow{2}{*}{\multicolumn{2}{|c|}{ Departamento }} & \multicolumn{2}{|c|}{$\begin{array}{c}\text { ¿Usted está de acuerdo con la } \\
\text { continuidad del proceso de cambio } \\
\text { liderizado por el Presidente Evo } \\
\text { Morales Ayma y el Vicepresidente } \\
\text { Álvaro García Linera? }\end{array}$} & \multicolumn{2}{|c|}{$\begin{array}{l}\text { ¿Usted está de acuerdo } \\
\text { con la continuidad de las } \\
\text { políticas, las acciones y } \\
\text { la gestión del Prefecto del } \\
\text { Departamento? }\end{array}$} \\
\hline & & Votación & $\%$ & Votación & $\%$ \\
\hline \multirow{2}{*}{$\begin{array}{l}\text { CÓMPUTO } \\
\text { NACIONAL }\end{array}$} & SI & 2.103 .872 & $67,41 \%$ & & \\
\hline & NO & 1.017 .037 & $32,59 \%$ & & \\
\hline \multicolumn{6}{|c|}{ Presidente ratificado: Evo Morales Ayma (MAS) } \\
\hline \multirow{2}{*}{ CHUQUISACA } & SI & 92.616 & $53,88 \%$ & & \\
\hline & NO & 79.266 & $46,12 \%$ & & \\
\hline \multicolumn{6}{|c|}{ Prefecta Savina Cuéllar. no fue sometida a votación } \\
\hline \multirow{2}{*}{ LA PAZ } & SI & 885.028 & $83,27 \%$ & 364.214 & $35,48 \%$ \\
\hline & NO & 177.772 & $16,73 \%$ & 662.259 & $64,52 \%$ \\
\hline \multicolumn{6}{|c|}{ Prefecto Revocado: José Luis Paredes (PODEMOS) } \\
\hline \multirow{2}{*}{ СОСНАВАМВА } & SI & 402.681 & $70,90 \%$ & 195.290 & $35,19 \%$ \\
\hline & NO & 165.276 & $29,10 \%$ & 359.602 & $64,81 \%$ \\
\hline \multicolumn{6}{|c|}{ Prefecto Revocado: Manfred Reyes Villa (AUN) } \\
\hline \multirow{2}{*}{ SANTA CRUZ } & SI & 273.525 & $40,75 \%$ & 451.191 & $66,43 \%$ \\
\hline & NO & 397.670 & $59,25 \%$ & 228.041 & $33,57 \%$ \\
\hline \multicolumn{6}{|c|}{ Prefecto Ratificado: Rubén Darío Costas Aguilera (APB) } \\
\hline \multirow{2}{*}{ PANDO } & SI & 13.753 & $52,50 \%$ & 14.841 & $56,21 \%$ \\
\hline & NO & 12.445 & $47,50 \%$ & 11.564 & $43,79 \%$ \\
\hline \multicolumn{6}{|c|}{ Prefecto Ratificado: Leopoldo Fernández Ferreira (PODEMOS) } \\
\hline \multirow{2}{*}{ BENI } & SI & 43.146 & $43,72 \%$ & 64.866 & $64,25 \%$ \\
\hline & NO & 55.542 & $56,28 \%$ & 36.091 & $35,75 \%$ \\
\hline \multicolumn{6}{|c|}{ Prefecto Ratificado: Ernesto Suarez Sattori (PODEMOS) } \\
\hline \multirow{2}{*}{ TARIJA } & SI & 66.645 & $49,83 \%$ & 78.170 & $58,06 \%$ \\
\hline & NO & 67.102 & $50,17 \%$ & 56.474 & $41,94 \%$ \\
\hline \multicolumn{6}{|c|}{ Prefecto Ratificado: Mario Adel Cossio Cortez (Encuentro Regional) } \\
\hline \multirow{2}{*}{ POTOSI } & SI & 185.317 & $84,87 \%$ & 171.629 & $79,08 \%$ \\
\hline & NO & 33.029 & $15,13 \%$ & 45.390 & $20,92 \%$ \\
\hline \multicolumn{6}{|c|}{ Prefecto Ratificado: Mario Virreira Iporre (MAS) } \\
\hline \multirow{2}{*}{ ORURO } & SI & 141.161 & $82,99 \%$ & 84.447 & $50,85 \%$ \\
\hline & NO & 28.935 & $17,01 \%$ & 81.620 & $49,15 \%$ \\
\hline \multicolumn{6}{|c|}{ Prefecto Ratificado: Alberto Luis Aguilar Calle (MAS) } \\
\hline
\end{tabular}


En la segunda gestión de Evo Morales la oposición regional estaba notablemente debilitada y no apoyó en bloque a un candidato presidencial. La victoria de Evo Morales en los comicios generales de diciembre de 2009 fue contundente, y a partir de esta gestión el gobierno emprendería un camino hacia las autonomías dentro de las directrices de la nueva CPE. La oposición regional no tenía un proyecto con peso a escala nacional, y el resultado fue una menguada oposición en la Asamblea Legislativa.

En las Elecciones Departamentales y Municipales de abril de 2010 se reeligieron tres gobernadores opositores en Santa Cruz, Beni y Tarija dentro un contexto de autonomía departamental, enmarcada en la nueva CPE. En occidente, con amplia base electoral a favor del MAS, vencieron los cinco candidatos oficialistas a gobernador (ver Cuadro 4). Del total de nueve departamentos del país, seis son oficialistas y tres opositores. Se debe destacar el surgimiento de candidatos para alcalde de partidos alternativos que restaron votos al MAS en varias capitales de departamento ${ }^{9}$ (ver Cuadro 5). El partido de gobierno logró amplia representación en las Asambleas Legislativas Departamentales. Los resultados electorales dibujarían nuevas interacciones, poderes regionales que favorecerían al oficialismo aun en los departamentos con autoridades opositoras.

Los medios de comunicación privados de cobertura nacional, en su mayoría, son controlados por empresarios quienes, en una postura muy crítica hacia el gobierno, tomaron partido por la oposición regional y parlamentaria, sobre todo en la primera gestión de Evo Morales. En consecuencia, la confrontación era frecuente, difícilmente el gobierno podía regularlos, sin ser acusado de atentar contra la libertad de expresión. Para enfrentar la oposición mediática el gobierno tomó la alternativa de crear sus propios medios y dinamizar los existentes. Se crearon el periódico Cambio y un sistema nacional de radioemisoras de los pueblos originarios, mientras que se dinamizó el canal estatal de TV, y la cobertura de la Agencia Boliviana de Información en la red Internet. Evo Morales pretendió normar los medios "para que no mientan"10, estas declaraciones levantaron susceptibilidades respecto a la libertad de expresión. Se proyectó la Ley de Medios y Comunicación, según los principios de la nueva CPE: "libertad de expresión, derecho a la réplica, a la rectificación, cláusula de conciencia, el derecho a la comunicación e información, la veracidad y responsabilidad" (Iván Canelas, vocero de gobierno, Radio Erbol 14 de Junio de 2010). Recientemente, los medios ablandaron su postura de crítica extrema, a la vez que los paquetes accionarios de algunos medios, como los periódicos La Razón y Extra y la red televisiva ATB, fueron adquiridos por capitales venezolanos ${ }^{11}$, con un previsible giro de sus tendencias. 
Cuadro 4. Elecciones departamentales 2010: resultados para gobernador

\begin{tabular}{|c|c|c|c|c|}
\hline Departamento & Organización Política & votación & porcentaje & $\begin{array}{l}\text { Gobernador } \\
\text { Electo }\end{array}$ \\
\hline \multirow{5}{*}{ CHUQUISACA } & $\begin{array}{l}\text { Movimiento Al Socialismo } \\
\text { - Instrumento Político por la } \\
\text { Soberanía de los Pueblos (MAS- } \\
\text { IPSP) }\end{array}$ & 109.270 & $53,60 \%$ & \multirow{5}{*}{$\begin{array}{c}\text { Esteban } \\
\text { Urquizu } \\
\text { Cuellar } \\
\text { (MAS-IPSP) }\end{array}$} \\
\hline & Chuquisaca Somos Todos (CST) & 72.314 & $35,50 \%$ & \\
\hline & $\begin{array}{l}\text { Libertad y Democracia } \\
\text { Renovadora (LIDER) }\end{array}$ & 8.752 & $4,30 \%$ & \\
\hline & Movimiento Sin Miedo (MSM) & 8.044 & $3,90 \%$ & \\
\hline & Falange F-19 (F-19) & 5.476 & $2,70 \%$ & \\
\hline \multirow{6}{*}{ LA PAZ } & MAS-IPSP & 534.563 & $50,00 \%$ & \multirow{6}{*}{$\begin{array}{l}\text { Cesar Hugo } \\
\text { Cocarico } \\
\text { Yana (MAS } \\
\text { IPSP) }\end{array}$} \\
\hline & Movimiento Sin Miedo (MSM) & 247.796 & $23,20 \%$ & \\
\hline & Frente de Unidad Nacional (UN) & 159.499 & $14,90 \%$ & \\
\hline & $\begin{array}{l}\text { Movimiento Por la Soberanía } \\
\text { (MPS) }\end{array}$ & 67.863 & $6,30 \%$ & \\
\hline & Alianza Social Patriótica (ASP) & 30.361 & $2,80 \%$ & \\
\hline & $\begin{array}{l}\text { Movimiento Nacionalista } \\
\text { Revolucionario (MNR) }\end{array}$ & 29.152 & $2,70 \%$ & \\
\hline \multirow{4}{*}{ COCHABAMBA } & MAS-IPSP & 415.245 & $61,90 \%$ & \multirow{4}{*}{$\begin{array}{l}\text { Edmundo } \\
\text { Novillo } \\
\text { Aguilar } \\
\text { (MAS-IPSP) }\end{array}$} \\
\hline & $\begin{array}{l}\text { Unidad Nacional-Convergencia } \\
\text { Patriótica (UN-CP) }\end{array}$ & 174.175 & $26,00 \%$ & \\
\hline & Movimiento Sin Miedo (MSM) & 52.516 & $7,80 \%$ & \\
\hline & $\begin{array}{l}\text { Movimiento Nacionalista } \\
\text { Revolucionario (MNR) }\end{array}$ & 29.250 & $4,40 \%$ & \\
\hline \multirow{4}{*}{ ORURO } & MAS-IPSP & 107.576 & $59,6 \%$ & \multirow{4}{*}{$\begin{array}{l}\text { Santos Javier } \\
\text { Tito } \\
\text { Véliz (MAS- } \\
\text { IPSP) }\end{array}$} \\
\hline & Movimiento Sin Miedo (MSM) & 53.111 & $29,4 \%$ & \\
\hline & Frente de Unidad Nacional (UN) & 13.933 & $7,7 \%$ & \\
\hline & $\begin{array}{l}\text { Movimiento Nacionalista } \\
\text { Revolucionario (MNR) }\end{array}$ & 5.800 & $3,2 \%$ & \\
\hline \multirow{5}{*}{ POTOSÍ } & MAS-IPSP & 163.989 & $66,80 \%$ & \multirow{5}{*}{$\begin{array}{l}\text { Félix } \\
\text { Gonzáles } \\
\text { Bernal } \\
\text { (MAS-IPSP) }\end{array}$} \\
\hline & Alianza Social (AS) & 31.564 & $12,90 \%$ & \\
\hline & $\begin{array}{l}\text { Agrupación Ciudadana } \\
\text { Uqharikuna (ACU) }\end{array}$ & 27.873 & $11,40 \%$ & \\
\hline & $\begin{array}{l}\text { Frente Cívico Regional } \\
\text { Potosinista (FCRP) }\end{array}$ & 15.960 & $6,50 \%$ & \\
\hline & $\begin{array}{l}\text { Movimiento Nacionalista } \\
\text { Revolucionario (MNR) }\end{array}$ & 6.066 & $2,50 \%$ & \\
\hline
\end{tabular}




\begin{tabular}{|c|c|c|c|c|}
\hline \multirow{3}{*}{ PANDO } & MAS-IPSP & 17.192 & $49,70 \%$ & \multirow{3}{*}{$\begin{array}{l}\text { Luis Adolfo } \\
\text { Flores } \\
\text { Roberts } \\
\text { (MAS-IPSP) }\end{array}$} \\
\hline & Consenso Popular (CP) & 16.744 & $48,40 \%$ & \\
\hline & Movimiento Sin Miedo (MSM) & 657 & $1,90 \%$ & \\
\hline \multirow{6}{*}{ SANTA CRUZ } & VERDES & 515.370 & $52,60 \%$ & \multirow{6}{*}{$\begin{array}{c}\text { Rubén } \\
\text { Armando } \\
\text { Costas } \\
\text { Aguilera } \\
\text { (VERDES) }\end{array}$} \\
\hline & (MAS-IPSP) & 374.326 & $38,20 \%$ & \\
\hline & Todos por Santa Cruz (TODOS) & 43.929 & $4,50 \%$ & \\
\hline & Frente Amplio (FA) & 25.031 & $2,60 \%$ & \\
\hline & Movimiento Sin Miedo (MSM) & 11.530 & $1,20 \%$ & \\
\hline & $\begin{array}{l}\text { Fuerza Ciudadana Nacionalista } \\
(\mathrm{FCN})\end{array}$ & 8.937 & $0,90 \%$ & \\
\hline \multirow{3}{*}{ TARIJA } & $\begin{array}{l}\text { Camino al Cambio Alianza } \\
\text { Nacional (CC) }\end{array}$ & 97.726 & $48,90 \%$ & \multirow{3}{*}{$\begin{array}{l}\text { Mario Adel } \\
\text { Cossio } \\
\text { Cortez }(\mathrm{CC})\end{array}$} \\
\hline & MAS-IPSP & 88.014 & $44,10 \%$ & \\
\hline & $\begin{array}{l}\text { Poder Autonómico Nacional } \\
\text { (PAN) }\end{array}$ & 13.909 & $7,00 \%$ & \\
\hline \multirow{5}{*}{ BENI } & Primero el Beni (PRIMERO) & 64.055 & $42,50 \%$ & \multirow{5}{*}{$\begin{array}{c}\text { Ernesto } \\
\text { Suárez } \\
\text { Sattori } \\
\text { (PRIMERO) }\end{array}$} \\
\hline & MAS-IPSP & 60.477 & $40,10 \%$ & \\
\hline & MNR - PUEBLO & 18.269 & $12,10 \%$ & \\
\hline & Convergencia Amazónica (CA) & 5.949 & $3,90 \%$ & \\
\hline & $\begin{array}{l}\text { Nacionalidades Autónomas por } \\
\text { el Cambio y Empoderamiento } \\
\text { Revolucionario (NACER) }\end{array}$ & 1.894 & $1,30 \%$ & \\
\hline
\end{tabular}

Fuente: elaboración propia con base en datos CNE. Disponibles en:

http://www.cne.org.bo/centro_doc/prensa virtual/gestion2010/EDM/Acta_computoEDM2010.zip

Los medios de comunicación privados de cobertura nacional, en su mayoría, son controlados por empresarios quienes, en una postura muy crítica hacia el gobierno, tomaron partido por la oposición regional y parlamentaria, sobre todo en la primera gestión de Evo Morales. En consecuencia, la confrontación era frecuente, difícilmente el gobierno podía regularlos, sin ser acusado de atentar contra la libertad de expresión. Para enfrentar la oposición mediática el gobierno tomó la alternativa de crear sus propios medios y dinamizar los existentes. Se crearon el periódico Cambio y un sistema nacional de radioemisoras de los pueblos originarios, mientras que se dinamizó el canal estatal de TV, y la cobertura de la Agencia Boliviana de Información en la red Internet. Evo Morales pretendió normar los medios "para que no mientan"10, estas declaraciones levantaron susceptibilidades respecto a la libertad de expresión. Se proyectó la Ley de Medios y Comunicación, según los principios de la nueva CPE: "libertad de expresión, derecho a la réplica, a la rectificación, cláusula de conciencia, el derecho a la comunicación e información, la veracidad y responsabilidad" (Iván Canelas, vocero de gobierno, Radio Erbol 14 de Junio de 2010). Recientemente, los medios ablandaron su postura de crítica extrema, a la vez que los paquetes accionarios de algunos medios, como los pe- 
riódicos La Razón y Extra y la red televisiva ATB, fueron adquiridos por capitales venezolanos ${ }^{11}$, con un previsible giro de sus tendencias.

Cuadro 5. Elecciones Municipales 2010: resultados para alcalde en capitales de departamento

\begin{tabular}{|c|c|c|c|c|}
\hline $\begin{array}{c}\text { Capital de } \\
\text { departamento }\end{array}$ & Alcalde electo & Sigla & $\begin{array}{l}\text { Votación por } \\
\text { alcalde electo }\end{array}$ & $\begin{array}{l}\text { Votación por el } \\
\text { MAS - IPSPP }\end{array}$ \\
\hline Sucre & $\begin{array}{l}\text { Jaime Barrón } \\
\text { Poveda }\end{array}$ & PAIS & $\begin{array}{r}57.854 \\
(47,2 \%)\end{array}$ & $\begin{array}{r}38.387 \\
(31,3 \%)\end{array}$ \\
\hline La Paz & $\begin{array}{l}\text { Luis Revilla } \\
\text { Herrero }\end{array}$ & MSM & $\begin{array}{l}226.010 \\
(48,5 \%)\end{array}$ & $\begin{array}{l}162.667 \\
(34,9 \%)\end{array}$ \\
\hline Cochabamba & $\begin{array}{l}\text { Edwin } \\
\text { Castellanos } \\
\text { Mendoza }\end{array}$ & $\begin{array}{l}\text { MAS - } \\
\text { IPSP }\end{array}$ & $\begin{array}{l}123.097 \\
(39,5 \%)\end{array}$ & $\begin{array}{l}123.097 \\
(39,5 \%)\end{array}$ \\
\hline Oruro & Rocío Pimentel & MSM & $\begin{array}{r}48.372 \\
(39.1 \%)\end{array}$ & $\begin{array}{r}41.382 \\
(33.4 \%)\end{array}$ \\
\hline Potosí & $\begin{array}{l}\text { Rene Joaquino } \\
\text { Cabrera }\end{array}$ & AS & $\begin{array}{r}44.887 \\
(52 \%)\end{array}$ & $\begin{array}{r}29.053 \\
(33,6 \%)\end{array}$ \\
\hline Tarija & $\begin{array}{l}\text { Oscar Montes } \\
\text { Barzon }\end{array}$ & UNIR & $\begin{array}{r}49.949 \\
(51 \%)\end{array}$ & $\begin{array}{r}24.375 \\
(24,9 \%)\end{array}$ \\
\hline $\begin{array}{l}\text { Santa Cruz de } \\
\text { la Sierra }\end{array}$ & $\begin{array}{l}\text { Percy Fernandez } \\
\text { Añez }\end{array}$ & SPT & $\begin{array}{l}342.223 \\
(55,5 \%) \\
\end{array}$ & $\begin{array}{l}196.868 \\
(31,9 \%) \\
\end{array}$ \\
\hline Trinidad & $\begin{array}{l}\text { Moises Shriqui } \\
\text { Vejarano }\end{array}$ & PRIMERO & $\begin{array}{r}19.395 \\
(40,4 \%) \\
\end{array}$ & $\begin{array}{r}11.763 \\
(24,5 \%) \\
\end{array}$ \\
\hline Cobija & $\begin{array}{l}\text { Ana Lucia Reis } \\
\text { Melena }\end{array}$ & $\begin{array}{l}\text { MAS - } \\
\text { IPSP }\end{array}$ & $\begin{array}{r}10.704 \\
(53,5 \%) \\
\end{array}$ & $\begin{array}{r}10.704 \\
(53,5 \%) \\
\end{array}$ \\
\hline
\end{tabular}

Fuente: elaboración propia con base en datos CNE. Disponibles en:

http://www.cne.org.bo/centro doc/prensa virtual/gestion2010/EDM/Acta computoEDM2010.zip

Medidas para lograr una redistribución más equitativa del ingreso: políticas públicas de salud, educación, seguridad social

La agenda gubernamental se despliega siguiendo dos líneas de acción: la generación de excedente económico para la inversión en procesos de industrialización con protagonismo estatal, sobre todo en el sector de hidrocarburos y minería, y la redistribución de los ingresos fiscales mediante políticas sociales con cariz popular.

La política económica del gobierno de Evo Morales tiene como eje a la nacionalización de los recursos hidrocarburíferos. Al margen de la importancia de esta medida en el incremento de los ingresos fiscales y su repercusión en las posibilidades de impulso al desarrollo productivo, la nacionalización conlleva una reformulación de las relaciones entre el Estado boliviano y las empresas extranjeras y fue enarbolada como una respuesta al neoliberalismo. En la política del sector de hidrocarburos se percibe con nitidez un rasgo del estilo de gestión gubernamental 
del MAS que consiste en la combinación de retórica radical con decisiones moderadas puesto que, pese a la toma simbólica de las instalaciones petroleras con presencia de las Fuerzas Armadas, el decreto presidencial promulgado el 1 de mayo de 2006 no estableció la confiscación de inversiones sino una reformulación de los contratos con las empresas extranjeras fijando condiciones tributarias más favorables para el Estado boliviano. El impacto económico de esta medida fue evidente $\mathrm{y}$, adicionalmente, el gobierno negoció con Argentina y Brasil un incremento en los volúmenes y los precios del gas boliviano exportado a esos países, generando mayores ingresos fiscales. Si a eso sumamos la condonación de la deuda externa bilateral y multilateral, las condiciones económicas se tornaron favorables y se pusieron en evidencia en la balanza comercial. Y todo ello a pesar del contexto negativo provocado por la crisis financiera global.

En cuanto a la política laboral se aprobaron disposiciones dirigidas a eliminar la libre contratación y la flexibilización laboral -pilares del neoliberalismo-que habían provocado el debilitamiento de los sindicatos obreros desde la aplicación de un decreto presidencial en 1985. El decreto 28.699, promulgado en mayo de 2006, deroga un par de artículos de aquella medida de los años ochenta y su objetivo de restituir los derechos laborales se reforzó con la promulgación de una Ley del Fuero Sindical. Este decreto fue presentado por el gobierno como el "fin de la libre contratación y la garantía para la estabilidad laboral" pero es cuestionado por su limitado carácter formal puesto que la misma disposición reconoce la vigencia de la Ley de Inversiones que permite la libre contratación, contradiciendo las consecuencias de una medida anunciada como la recuperación de la estabilidad laboral en el sector público y privado. La nueva Ley de Pensiones, todavía en debate, consiste en la creación del sistema mixto estatal-privado, cuyas fuentes de ingresos serán el aporte laboral, patronal y estatal, y serán administrados por una entidad pública, en vez de las empresas transnacionales de administración de fondo de pensiones. El sistema mixto fue cuestionado por la posibilidad de utilización de sus recursos, en caso de déficit estatal. La apertura a sectores independientes da a la nueva Ley de Pensiones un carácter de universalidad, puesto que absorberá al sector de trabajo informal, terciario y agrícola. Se propone la creación de un Fondo Solidario que permitiría elevar la pensión de acuerdo al salario mínimo. También se pretende reducir la edad de jubilación a 58 años, y para el caso de los trabajadores mineros se reducirá en 2 años más por insalubridad laboral. Además, se propuso una figura que adelanta la jubilación de las mujeres, por cada hijo nacido vivo. El proyecto de Ley de Pensiones fue el resultado de una intensa deliberación con la Central Obrera Boliviana, máxima instancia sindical laboral.

La política macroeconómica, en los últimos veinte años, estuvo concentrada en sectores de alta inversión y el aparato productivo especializado en la extracción de recursos naturales que, si bien produce excedentes monetarios, no genera empleos de manera efectiva. Esto repercute en un mercado laboral ya marcadamente informal, con un comercio que también comprende lo ilegal. ${ }^{12}$ Sólo una minoría de los trabajadores tiene un empleo formal y la posibilidad de afiliarse a la seguridad social. La política del actual gobierno dio un giro estatista contrario al neoliberal. 
El Estado interviene directamente en la transformación productiva, sin embargo, aún no se ha diversificado la producción de manera que permita crear empleos de calidad.

En relación con la política tributaria, lo central se refiere a la redistribución de los ingresos provenientes del Impuesto Directo a los Hidrocarburos que, desde el año 2005, era repartido entre el Tesoro General de la Nación, las prefecturas, los municipios, las universidades públicas y un fondo de apoyo a los pueblos indígenas. En octubre de 2007, el gobierno emitió un decreto modificando la asignación de esos recursos para beneficiar a los municipios en detrimento de las prefecturas. Adicionalmente, el gobierno alentó la aprobación de una ley (Renta Universal de Vejez) que establece el uso del treinta por ciento de esos recursos (de prefecturas, municipios, fondo indígena y TGN) al pago de una renta mensual a las personas de la tercera edad. Tanto el decreto como la ley fueron cuestionados por la oposición parlamentaria y los prefectos, porque afectaba los ingresos de las regiones que promovían su autonomía departamental, mientras que el gobierno argumentaba que los impuestos estarían destinados a beneficiar a los sectores sociales desprotegidos. En octubre de 2008, después de una escalada de conflictos, se logró un preacuerdo entre gobierno y regiones para la restitución parcial de estos fondos a las prefecturas. En la Ley Marco de Autonomías -aprobada en la presente gestión-se tiene previsto introducir criterios para habilitar un pacto fiscal que posibilite una nueva redistribución de recursos tributarios.

Otras decisiones gubernamentales están destinadas a beneficiar a comunidades campesinas y pueblos indígenas a partir de privilegiar derechos colectivos. Por ejemplo, en el caso del acceso a la tierra, la modificación de la ley 1.715, bajo el título de Reconducción Comunitaria de la Reforma Agraria, beneficiará a campesinos e indígenas con 20 millones de hectáreas concedidas a comunidades y no a título individual. La redistribución de tierras será un proceso complicado puesto que pretende resolver las falencias de la Reforma Agraria de 1952 que, en la región occidental del país, resultó en un excesivo fraccionamiento de tierras, a la vez que en la región oriental permitió la propiedad de grandes extensiones.

Entre las políticas públicas en educación -gracias a convenios con Cuba y Venezuela-, se destaca la campaña de alfabetización en la que se graduaron más de 800 mil personas. En enero de 2009 el gobierno declaró a Bolivia "libre de analfabetismo". Algunas críticas cuestionaron la efectividad del programa y observaron su aplicación con afanes electorales y de promoción de la figura presidencial. Este programa se amplía con la post-alfabetización, que consiste en impartir educación primaria a los alfabetizados y personas mayores de 15 años. Hasta el año 2009, 52.627 personas fueron beneficiadas con el programa de post-alfabetización. Entre las políticas de educación se destaca también la implementación del bono Juancito Pinto destinado a reducir el abandono escolar, mediante la entrega de 200 bolivianos a cada niño de nivel primario de colegio fiscal, a condición de terminar el año académico. Seis millones de bonos ya fueron otorgados entre 2006 y 2009. Este programa fue criticado por aplicarse en función de la coyuntura electoral y por la intervención de niños en actos proselitistas. Aún es pronto para contar con datos 
empíricos sobre el alcance de las medidas gubernamentales respecto al abandono escolar. La descentralización administrativa llevada a cabo desde los años noventa logró que los municipios determinen en sus planes de desarrollo una inversión más eficaz en educación, de acuerdo a requerimientos locales. Aún así, persiste la desigualdad en el acceso a la educación en poblaciones marginadas y áreas rurales respecto a áreas urbanas.

En relación con la educación superior, se crearon universidades indígenas a fin de fortalecer y preservar las culturas originarias. El Comité Ejecutivo de la Universidad Boliviana planteó que las universidades deben ser creadas a partir de la desconcentración de la universidad actual y que la creación de universidades por parte del gobierno atenta contra la autonomía universitaria al subordinarla al Ministerio de Educación. Algunas autoridades universitarias consideraron al proyecto como discriminatorio porque al enseñar sólo en idiomas nativos se genera mayor segregación y las universidades indígenas podrían convertirse en guetos educativos. ${ }^{13}$ Por su parte, los propios indígenas allegados a estas nuevas universidades solicitaron que la formación académica sea impartida de manera mixta (idioma nativo y castellano).

En la implementación de políticas sociales con sello popular resaltan varias iniciativas, algunas matizadas por la cooperación de los gobiernos de Venezuela y Cuba. Las campañas en salud y educación se despliegan con apoyo de esos países. En el sector de salud se amplió la cobertura del seguro materno-infantil ${ }^{14}$ aunque con poca efectividad por el desconocimiento por parte de la población beneficiada. Como parte del programa cubano Operación Milagro, médicos cubanos operaron entre 2005-2009 a 441 mil personas que padecían enfermedades oculares. Se implementó el bono Juana Azurduy, programa para reducir la mortalidad materno-infantil que consiste en montos entregados por acudir a consulta médica de control prenatal, postparto y consultas bimestrales hasta que el niño cumpla dos años. Hasta agosto de 2009 fueron beneficiadas 289 mil personas. Algunas voces críticas cuestionaron su sostenibilidad porque no está previsto en el presupuesto general de la nación, y por su implementación en coyuntura preelectoral. El bono tuvo dificultades por retrasos en la inscripción y el pago de este beneficio. La aprobación congresal de un seguro universal de salud está en curso $^{15}$, como parte de las tareas que deberá encarar el gobierno en la presente gestión.

El gobierno presentó algunas políticas de seguridad social, entre ellas destaca la Renta Universal de Vejez (Renta Dignidad), por la que las personas mayores de 60 años reciben 200 bolivianos mensuales. Entre 2008 y 2009 el programa alcanzó a 757 mil beneficiados. La Renta Universal de Vejez fue una política de anteriores gobiernos, la fuente de recursos para su aplicación fue ambulante, porque durante el neoliberalismo se sostuvo con los fondos de las empresas capitalizadas, y en el gobierno de Evo Morales la fuente provino del recorte al Impuesto Directo a los Hidrocarburos. Es otra de las medidas consideradas como políticas con un fuerte discurso populista, pero esta vez la intención parecía apuntar a socavar las economías de los gobiernos departamentales, especialmente opositores. A partir 
del momento en que se aplican este tipo de medidas se convierten en derechos adquiridos y se transforman en una obligación ineludible del gasto público que, en algunos casos, debe solventarse con deuda externa o interna, y con su consecuente pago de intereses y capital a mediano plazo. Esto lo convierte en un beneficio temporal de transmisión directa de recursos que, a mediano plazo, podría resultar en depauperación de la población.

Las políticas de redistribución equitativa del ingreso siguen la filosofía de la solidaridad y del "vivir bien" que es impulsada por el gobierno. Otra de las decisiones fue la aplicación de una tarifa diferenciada en el consumo de energía eléctrica, que benefició a más de medio millón de familias con bajos ingresos, con un descuento de $25 \%$. Este programa significa un ahorro de 130 millones de bolivianos para la población pero la sostenibilidad de este beneficio -basado en convenios con el Estado-, está en duda, puesto que se financia con los aportes de las propias empresas de generación, transmisión y distribución de energía. A fin de llegar a los sectores más empobrecidos, mediante el Plan Nacional de Vivienda Social y Solidaria, el Estado ha otorgado créditos para la construcción de viviendas sociales. Según datos oficiales, hasta 2009, se construyeron 33.622 viviendas sociales. Como parte de la política crediticia y para paliar los efectos de la crisis económica internacional, se creó el Banco de Desarrollo Productivo (BDP), financiado en un $80 \%$ por el Estado y en $20 \%$ por la Corporación Andina de Fomento. El BDP concede créditos individuales y asociativos de producción con bajas tasas de interés, y dos años de gracia a la empresa mediana y grande. Según datos oficiales, hasta 2009, se otorgaron créditos por un monto de 1.065 millones de bolivianos con la intención de generar empleos directos e indirectos. Estos son los lineamientos y esfuerzos del gobierno para procurar una redistribución solidaria y equitativa de los recursos.

El gobierno implementó también una política de austeridad recortando los salarios de los servidores públicos de la esfera gubernamental. Así el Presidente bajó su sueldo un $57 \%$ y $50 \%$ a ministros, viceministros y directores, lo que redujo el gasto de la escala salarial en 24 millones de bolivianos, cifra que cubriría nuevos ítems de educación y salud, aunque provocando una merma en la presencia de personal especializado en la conducción de varias instancias estatales. Se impulsó también la transparencia de recursos de la gestión pública por la reducción de "gastos reservados" que en anteriores gobiernos ascendían hasta 30 millones de dólares de egresos sin fiscalizar ${ }^{16}$, dando continuidad a la reducción de este presupuesto que fue iniciativa del presidente Carlos Mesa. Sin embargo, existen grandes recursos provenientes de préstamos y aportes venezolanos que no pasan por los conductos regulares de auditoría y fiscalización, entre ellos se encuentran los cheques venezolanos que el presidente Morales ha otorgado a los municipios en el marco del Programa "Bolivia cambia, Evo cumple".

\section{El giro en las relaciones internacionales}

La política exterior dio un giro respecto a sus predecesores, el gobierno boliviano reivindica soberanía y denuncia injerencia de los Estados Unidos; en esta direc- 
ción, suspendió las operaciones de la DEA y limitó las actividades de USAID. La medida más drástica que tuvo el gobierno fue la expulsión del embajador Phillip Golberg, el 10 de octubre de 2008, acusándolo de "injerencia política, espionaje, financiamiento y apoyo a actividades golpistas cívico-prefecturales". La réplica de EE.UU. resultó en la expulsión del embajador boliviano y la suspensión del programa ATPDEA ${ }^{17}$ que otorgaba beneficios arancelarios de exportación a los países andinos que se alineaban a las políticas americanas de lucha contra el narcotráfico. Esto significó la pérdida de un importante mercado de exportaciones, que el gobierno intenta reemplazar con la apertura de nuevos mercados. El gobierno de Evo Morales, propició un acercamiento con Venezuela y Cuba, a la vez que determinó un distanciamiento con EE.UU..

Bolivia es actualmente miembro pleno de la Comunidad Andina de Naciones (CAN), a la vez que es miembro asociado de MERCOSUR. Una de las iniciativas del actual gobierno pretendía convertir al país en miembro pleno del MERCOSUR, a tiempo de continuar en la CAN. Esta aspiración fue desaconsejada por el Instituto Boliviano de Comercio Exterior y por la Unidad de Análisis de Políticas Económicas y Sociales, puesto que las políticas arancelarias de ambos mercados son excluyentes. Las relaciones internacionales que lleva el MERCOSUR se centran en los contratos de exportación de gas con Argentina y Brasil. Sin embargo, MERCOSUR es una potencia a nivel agropecuario y agroindustrial; su cercanía a Bolivia crearía una competencia en la cual los agricultores bolivianos quedarían desfavorecidos. En la actualidad, el saldo comercial para Bolivia en el intercambio de productos agropecuarios con el MERCOSUR es negativo. Mientras tanto, la CAN atravesó su crisis más grave, por la salida de Venezuela y por la negativa de Bolivia a firmar tratados de libre comercio con Estados Unidos o con la Unión Europea, lo que hizo que Perú, Ecuador y Colombia iniciaran negociaciones bilaterales con la UE. La posición ideológica del gobierno ha alejado a Bolivia de sus socios de la CAN.

En 2004 surgió, por iniciativa venezolana, una alternativa antagónica al ALCA y al neoliberalismo; la Alianza Bolivariana para los Pueblos de Nuestra América/ Tratado de Comercio de los Pueblos (ALBA_TCP), a la cual se suscribieron primero Cuba (2004) y Bolivia (2006), luego Nicaragua, Honduras, y Ecuador, el último como miembro observador. Entre los principios de este acuerdo figura: "El ALBA es un proceso de integración que más allá de la unión económica o de los réditos que pretende proporcionar el capitalismo, se propone impulsar vínculos de solidaridad en una nueva concepción que surge de las ideologías del socialismo del Siglo XXI y en las ideas inmortales de nuestros libertadores". ${ }^{18}$ La integración bolivariana pretende la complementariedad y corrección de asimetrías, y propone acuerdos en el plano social, más allá del comercio. El apoyo de Venezuela tiene varios matices porque financia campañas propagandísticas del gobierno bajo el lema "Bolivia cambia, Evo cumple", realiza donaciones en dinero a los municipios y entrega recursos a las Fuerzas Armadas, al margen de que se ha suscrito un convenio de cooperación militar entre Bolivia y Venezuela, cuestionado por la oposición. Por estas razones, el discurso de la oposición reitera denuncias de 
"injerencia" de Hugo Chávez en asuntos internos debido, entre otras cosas, a las continuas declaraciones del Presidente venezolano en respaldo a Evo Morales. Hasta 2009, Bolivia invirtió más de 25 millones de dólares en el marco del TCP; también suscribió la iniciativa de integración UNASUR, Unión de Naciones Suramericanas (creada en 2008), que plantea la unidad de las naciones del sur del continente en aspectos políticos, económicos, sociales, culturales, ambientales, energéticos y de infraestructura.

Un tema fundamental de las relaciones internacionales es la política marítima, basada en la premisa constitucional de recuperar una salida soberana al océano Pacífico. El acercamiento a Chile, durante la presidencia de Michelle Bachelet, permitió incorporar una agenda de trece puntos entre los que se encuentra el tema de la demanda marítima boliviana. El gobierno boliviano actual descartó la utilización de la figura "gas por mar", que se propuso en el Referéndum de Hidrocarburos de 2004 como una posibilidad abierta de acuerdo. En el avance de negociaciones sobre la demanda histórica boliviana, surgió como punto crítico y traba, una demanda interpuesta por Perú al tribunal de la Haya por límites territoriales del espacio marítimo con Chile. A pesar del optimismo, el gobierno no logró avances significativos sobre este tema, que momentáneamente quedó suspendido, luego del terremoto en Chile y de la asunción del nuevo mandatario, Sebastián Piñera. Al retomar el tema, el nuevo Presidente chileno declaró que su país no cederá soberanía sobre su espacio marítimo, y que no pretende crear falsas expectativas, puesto que se ceñirá al Tratado de Paz y Amistad de 1904. No obstante, muchas de las condiciones de este tratado perdieron vigencia, entre ellas el libre derecho de tránsito a perpetuidad, ya que los puertos chilenos pasarán a manos privadas, las que no heredarán las obligaciones del Estado. El enclaustramiento de Bolivia tiene repercusiones internacionales, puesto que es un obstáculo para la concreción de la integración carretera bioceánica y para mayores avances en la integración energética del Cono Sur.

Las relaciones de Bolivia con Perú pasaron por momentos críticos. La firma del TLC de Perú con Estados Unidos generó una disputa ideológica en el interior de la CAN. También hubo un conflicto contra los indígenas en Bagua por la firma del TLC; en consecuencia, Alan García acusó a Evo Morales y a Hugo Chávez de conspiración internacional. Otro momento crítico fue el surgimiento de una situación tripartita que frenaba los avances en las aspiraciones marítimas de Bolivia, por una demanda que Perú interpuso en el tribunal de la Haya contra Chile por límites en el litoral. Otro impasse diplomático con Perú fue la concesión de asilo político a tres ex ministros del gobierno de Gonzalo Sánchez de Lozada, acusados de participación en un gobierno presuntamente genocida. ${ }^{19}$ Las diferencias ideológicas entre los mandatarios complican las relaciones entre estas naciones que siempre han sido aliadas históricas.

Un aspecto destacable fue que Bolivia obtuvo una reducción del $50 \%$ de la deuda externa que tenía en 2004, gracias a las condonaciones en los años 2006-2008, como país acreedor a la iniciativa HIPC y la Iniciativa de Deuda Multilateral. No obstante, y aún con superávit fiscal, se han seguido contrayendo deudas; en 2007, se endeudó por 998 millones y en 2008 por 1.205 millones de dólares, principal- 
mente con la Argentina, Venezuela y Brasil por la importación de diesel y otros derivados. Según un reporte de la Fundación Jubileo ${ }^{20}$, la deuda externa del país hasta el 2009 fue de 2.547 millones de dólares. Aunque el gobierno ha manifestado que no estaba dispuesto a someterse a los organismos multilaterales como en el pasado, los principales acreedores son el Banco Interamericano de Desarrollo (BID), el Banco Mundial (BM), la Corporación Andina de Fomento (CAF), y España.

Otro aspecto de las relaciones internacionales del Estado Plurinacional de Bolivia fue la apertura de relaciones con Irán, que despertó críticas y advertencias de EE.UU. y del Consejo de Seguridad de la ONU, alegando que ese país estaría bajo sospecha de enriquecer uranio para la fabricación de armas nucleares, y porque además de establecer una alianza en temas políticos, económicos y energéticos, se propuso el desarrollo de la tecnología nuclear con fines pacíficos. Por otra parte, Bolivia y Venezuela rompieron relaciones diplomáticas con Israel por la ofensiva en Gaza el 15 de enero de 2009. Evo Morales anunció la ruptura con Israel en señal de solidaridad con el pueblo palestino; ante el cuerpo diplomático acreditado en La Paz denunció que "los crímenes del gobierno de Israel afectan la estabilidad y paz mundial, y han hecho retroceder al mundo a la peor etapa de los crímenes de lesa humanidad, que no se habían vivido en la Segunda Guerra Mundial y en los últimos años en la ex Yugoslavia y Ruanda". Por lo demás, el gobierno de Evo Morales ha firmado acuerdos de cooperación con España, Japón, China, Suecia, Rusia, Canadá, la Unión Europea, Bélgica, Dinamarca, República de Corea. Pero, sobre todo, se debe subrayar que las relaciones exteriores tomaron un giro hacia la resuelta postura antiimperialista de Cuba y Venezuela.

\section{Logros y asignaturas pendientes}

Es innegable que la gestión de gobierno de Evo Morales ha promovido cambios y logros en un país de difícil gobernabilidad: la redacción de una nueva CPE; la incorporación activa de actores -antes socialmente excluidos-, en instituciones y espacios de gobierno; también se ha definido a Bolivia como un Estado Plurinacional y hubo cambios en la configuración territorial mediante la implementación de cuatro tipos de autonomía. Queda pendiente el proceso más complejo de la construcción de la nueva institucionalidad estatal.

Un logro importante fue la ampliación de la democracia a partir de la aplicación de instituciones como el referéndum, en tanto mecanismo de democracia participativa y la elección de autoridades y representantes indígenas según usos y costumbres, como expresión de democracia comunitaria, también reconocida en la Constitución. La organización del Estado Plurinacional ha determinado mayor representatividad con la adición de un senador por departamento, más la incorporación de siete escaños indígenas y la condición de paridad de género para cargos públicos. Otro avance fue la modernización de las elecciones que creció en eficacia hasta llegar a bolivianos residentes en el exterior, con un padrón electoral biométrico que ha inspirado mayor confiabilidad y seguridad. En un escenario donde cambian profundamente las instituciones, se hace necesario establecer programas 
de formación especializada en la organización, administración y gestión de los poderes públicos para lograr un mejor desempeño de los que ejercen estas funciones. En la operatividad de los objetivos de la nueva CPE queda pendiente propiciar condiciones para la convivencia del derecho positivo con el derecho consuetudinario, la conciliación de los derechos individuales con los derechos colectivos. Otra asignatura pendiente es exhibir en dinámica permanente y transparente, la independencia y equilibrio de los poderes públicos, garantizando el pluralismo en la representación política.

En las relaciones internacionales, se destaca desde el criterio del gobierno como un rescate de soberanía y dignidad, la voluntad expresa de no permitir la injerencia de Estados Unidos en asuntos internos como en el pasado. Sobresale un viraje afín a Venezuela y Cuba, países con los que se abren nuevas alternativas de comercio internacional. Queda pendiente el fortalecimiento de los acuerdos comerciales existentes con la CAN en calidad de miembro pleno. También se deberán evaluar objetivamente las condiciones de integración al MERCOSUR, antes de programar la membresía plena de este acuerdo comercial. Un tema central de las relaciones internacionales de Bolivia, que concierne a la integración regional, es la demanda marítima y las relaciones con Chile. Esta gestión al establecer un acercamiento entre los mandatarios de los dos países en 2006, ha logrado una agenda de trece puntos, que incluye la negociación de una salida al océano Pacífico. El desafío pendiente será persistir en acuerdos con base en el principio irrenunciable de soberanía sobre una salida al mar, expresado en el nuevo texto constitucional.

La ampliación y visión empresarial del Estado ha alcanzado logros en cuanto a la nueva política distributiva; se destaca la obtención de mayores ingresos por hidrocarburos y aplicación de políticas de transferencia directa de recursos (bonos) a grupos socialmente excluidos. El desafío es que se garantice la sostenibilidad económica de todo programa que implique bono. Otro desafío es reorganizar la matriz económica productiva basada en la explotación de recursos del gas natural y de minería, buscando diversidad para evitar la concentración de una amplia población en empleos informales. Quedan pendientes acciones que favorezcan industrias variadas y sectores diversificados que requieren la apertura de mercados internacionales para sus productos, a fin de generar mayor empleo y de mejor calidad. Será necesario reducir las inequidades con políticas sociales en coordinación con las políticas económicas. Queda pendiente hacer efectivo un nuevo pacto fiscal que contemple los lineamientos de la actual estructura política económica que comprende las autonomías y la real dimensión del Estado Plurinacional.

\section{A manera de corolario}

En los últimos años se ha modificado el mapa político de América latina con victorias electorales de partidos, fuerzas o líderes políticos de izquierda. En el marco de esa idea genérica de "giro a la izquierda", de manera paulatina se fue imponiendo una taxonomía que distingue entre gobiernos socialdemócratas y gobiernos populistas. Los primeros corresponderían a algunos países del cono sur: Brasil, Uruguay y, en menor medida, Argentina, puesto que Chile dejó de pertenecer a ese 
bando con la victoria de Piñera. En cambio, el mundo andino sería el ámbito del populismo con Venezuela, Bolivia y Ecuador como casos expresivos, incluyéndose en esta lista a Paraguay. Algunas interpretaciones sustentan esta distinción en las características del sistema de partidos (su estabilidad o crisis), en los rasgos del liderazgo político (supremacía o subordinación respecto a la institucionalidad), en la orientación de la política económica (estatismo o mercado) o en las pautas de la cultura política (ciudadanía o corporativismo) (Garretón, 2006; Cheresky, 2006). ${ }^{21}$ En cierta medida estas distinciones se apoyan en un prejuicio "desarrollista" que vincula socialdemocracia a "civilización" y populismo a "barbarie". En esta veta, la noción de progresismo permite evadir parcialmente esas distinciones o antinomias para juzgar el estilo político del partido de gobierno así como la orientación de las políticas públicas, empero se corre el riesgo de ignorar la especificidad del proceso nacional y situarse en el plano de las generalidades. En nuestro análisis del proceso político boliviano enfocamos nuestra mirada en el modo de gobierno del régimen presidencialista porque a medida que ha transcurrido la gestión de Evo Morales, el proyecto político del MAS discurrió hacia un presidencialismo de mayoría con sesgo plebiscitario. Y en cuanto a los rasgos de la gestión gubernamental, en la aplicación de sus políticas sobresale la orientación redistributiva del uso del excedente generado por los ingresos de la nacionalización de los hidrocarburos y el sello popular de los beneficiarios.

En cuanto a la orientación ideológica es preciso resaltar que la victoria del MAS implicó el retorno de la izquierda al poder después de la fallida experiencia del primer gobierno democrático, la Unidad Democrática y Popular (1982-1984). Este retorno, no obstante muestra rasgos específicos porque a diferencia de la izquierda obrera y clasista de antaño, el MAS es un movimiento político que representa identidades y demandas campesinas y étnico-culturales, se asienta en un conglomerado de organizaciones sindicales, movimientos sociales y pueblos indígenas, esgrime un proyecto de nacionalismo estatista y despliega una política internacional afín a Venezuela y Cuba. Finalmente, se articula en torno al liderazgo de Evo Morales, "primer presidente indígena", dirigente de los sindicatos de campesinos productores de hoja de coca y figura relevante en el movimiento antiglobalización o altermundista.

Este "giro a la izquierda" en la política boliviana se enmarca en un proceso más amplio de transición estatal que, después de cinco años, implica la transformación de las relaciones entre el Estado y la inversión extranjera redefiniendo el patrón de desarrollo, la mutación en las relaciones entre el Estado y las regiones mediante un modelo de descentralización política con autonomías territoriales en el nivel subnacional, la ampliación de las reglas de participación y representación política con la inclusión de mecanismos de democracia participativa y el reconocimiento de democracia comunitaria, y finalmente, la metamorfosis del modelo de Estado-nación como comunidad política a partir del reconocimiento de derechos colectivos de los pueblos indígenas que se traduce en la instauración -ambigua y relativa- de un Estado Plurinacional. 


\section{Referencias}

1. Conferencia Mundial de los Pueblos sobre el Cambio Climático y los Derechos de la Madre Tierra. Construyendo el Movimiento Mundial de los Pueblos por la Madre Tierra: http://cmpcc.org/2010/03/18/ indigenas-la-pachamama-esta-enferma/.

2. La Patria, 6/01/2010.

3. La Patria, 6/01/2010.

4. El Día, 15/05/2010.

5. Notas televisivas, PAT, Cadena A y otras. Ver: http://www.ernestojustiniano.org/2009/12/he-manevo-quiere-el-poder-total.

6. En la primera gestión, el MAS tenía 72 de 130 diputados en la Cámara baja, pero en la Cámara de Senadores no llegaba a la mayoría; sólo contaba con 12 representantes, mientras que PODEMOS contaba con 13 representantes. UN y MNR, cada uno con un senador, tenían votos decisivos. En la presente gestión, el MAS domina ambas Cámaras de la recién formada Asamblea Legislativa Plurinacional. Tiene 88 de 130 diputados y 26 de 36 senadores, por lo que puede aplicar su mayoría parlamentaria en rápida aprobación de leyes.

7. Hubieron casos irregulares en la votación del Referéndum Revocatorio, como la votación con nombres de personas fallecidas, y se detectaron 212.556 casos de doble carnetización a nivel nacional. Ver: http://www.laconstituyente.org/?q=node/2267.

8. En el poblado de El Porvenir, departamento de Pando, se dieron fuertes enfrentamientos entre civiles que dejaron un saldo de 11 muertos y decenas de heridos. El prefecto Leopoldo Fernández fue acusado de promover esta violencia y fue encarcelado. Al presente, después de casi dos años en presidio, aún espera un juicio.

9. En La Paz, ganó Luis Revilla, del Movimiento Sin Miedo (MSM); en Potosí, René Joaquino, de la Alianza Social; en Sucre, Jaime Barrón de Pacto de Integración Social (PAIS); y en Oruro, Rocío Pimentel, del MSM. Estos alcaldes de partidos opositores con naciente fuerza electoral surgen en las capitales de departamentos con amplia mayoría oficialista.

10. Los Tiempos, 26/01/2010.

11. La Prensa, $7 / 10 / 2009$.

12. Véase Wanderley (2009).

13. El Deber, $3 / 08 / 2008$.

14. El SUMI otorgaba prestaciones gratuitas a niños menores de 5 años y mujeres embarazadas desde el inicio del embarazo hasta los seis meses postparto. En diciembre de 2005 se sancionó la Ley $\mathrm{N}^{\circ} 3.250$ que amplió la cobertura del SUMI y brinda prestaciones a mujeres comprendidas entre las edades de 15 a 60 años, con el objeto de promover, además de una maternidad segura a las mujeres en edad fértil, la disminución de la incidencia de cáncer cérvico-uterino mediante la obligatoriedad en la prevención (examen de Papanicolaou anual) y el tratamiento de enfermedades de transmisión sexual.

15. Se pretende ampliar la cobertura del seguro para jóvenes entre 18 a 25 años. Las atenciones en salud crecieron de 13,5 millones en 2005 a 22 millones en 2009.

16. La mayor parte de los gastos reservados, en las gestiones de Hugo Banzer y de Gonzalo Sánchez de Losada fueron utilizados para conservar la fidelidad de las Fuerzas Armadas en tiempos de convulsión social.

17. Ley de Promoción Comercial Andina y Erradicación de la Droga (Andean Trade Promotion and Drug Eradication Act), reducciones arancelarias para productos procedentes de países andinos.

18. Declaración Conjunta sobre el ALBA, en Bolpress 11 de diciembre de 2009. Disponible en: http:// www.bolpress.de/art.php?Cod=2008110207

19. Durante la llamada "guerra del gas", la orden del gobierno de reprimir los conflictos con el ejército causó la muerte de 67 personas en la ciudad de El Alto, durante protestas contra el plan de exportación de gas por puerto chileno, en octubre de 2003.

20. Fundación Jubileo “¿Continúa la cadena de la deuda externa para Bolivia?”, en Reporte Coyuntura $N^{\circ} 8$, 2009. Consultar :

http://www.jubileobolivia.org.bo/recursos/files/pdfs/Reporte_Coyuntura_N_8__Deuda_Externa.pdf. 21. Véase D. Zovatto (2007); H. Cancino (2007). 


\section{Bibliografía}

H. CANCINO (2007), "La Izquierda latinoamericana en tiempos de globalización, 1990-2007”, en Sociedad y discurso, $\mathrm{N}^{\circ} 11$.

I. CHERESKY (2006), "Elecciones en América Latina: poder presidencial y liderazgo político bajo la presión de la movilización de la opinión pública y la ciudadanía", en Nueva Sociedad, N²06, Buenos Aires.

Fundación Jubileo (2009), “Continúa la cadena de la deuda externa para Bolivia?”, en Reporte Coyuntura, $\mathrm{N}^{\circ} 8$.

M. A. GARRETÓN (2006), "Modelos y liderazgos en América Latina, en Nueva Sociedad, № 205, Buenos Aires.

F. WANDERLEY (2009), "Bolivia: entre el cambio y la inercia. Empleo y bienestar en los últimos veinte años", en Revista Internacional del Trabajo, Vol. 128, $\mathrm{N}^{\circ} 3$.

F. YAKSIC (2010), "Desproporcional asignación de escaños en las asambleas departamentales", en Bolpress, 30 de abril. Disponible en: http://www.bolpress.com/art.php?Cod=2010043001.

D. ZOVATTO (2007), “América Latina después del «rally»electoral 2005-2006: algunas tendencias y datos sobresalientes", en Nueva Sociedad, N²07, Buenos Aires.

Recibido: 20/06/2010. Aceptado: 20/07/2010.

Fernando Mayorga y Benjamín Rodríguez, "Nacionalismo e indigenismo en el gobierno del MAS". Revista Temas y Debates. ISSN 1666-0714, año 14, número 20, octubre 2010, pp 97-122. 